\title{
Extracurricular activities of medical school applicants
}

\author{
Sang Hyun Kim
}

\author{
Department of Microbiology and Immunology, Kangwon National University School of Medicine, Chuncheon, \\ Korea
}

Purpose: The purpose of this study was to investigate medical school applicants' involvements in extracurricular activities including medical volunteering/community services, nonmedical community services, club activities, leadership role, and research.

Methods: Extracurricular characteristics were compared for 448 applicants (223 males and 225 females) who applied to Kangwon Medical School in 2013 to 2014. Frequency analysis, chi-square test, and simple correlation were conducted with the collected data. Results: The 448 applicants participated in medical volunteer/community services (15.3\%), nonmedical community services (39.8\%), club activities $(22.9 \%)$, club officials $(10 \%)$, and research $(13.4 \%)$. On average, applicants from foreign universities participated in 0.9 medical volunteer/community service, 0.8 nonmedical community service, 1.7 club activities, and 0.6 research work. On the other hand, applicants from domestic universities reported 0.2 medical volunteer/community service, 1.0 nonmedical community service, 0.7 club activity, and 0.3 research.

Conclusion: Involvement in extracurricular activities was extensive for medical school applicants. Participation in extracurricular activities differed between applicants from foreign and domestic universities. Females consistently reported greater participation in extracurricular activities than males. The data can be helpful for admission committees to recruit well-rounded applicants and compare between applicants with similar academic backgrounds.

Key Words: Extracurricular activity, Medical school, Admission

\section{Introduction}

Medical school admission committees are increasingly concerned with identifying desirable applicant qualities. Academic accomplishments used to gauge an applicants' predicted success are the primary standard in the selection of medical students [1]. Mitchell's review [1] showed that academic variables such as undergraduate grade point average (GPA) and medical education eligibility test (MEET) are important predictors in the selection. However, the emerging research into nonacademic variables reveals that extracurricular activities provide predictive power of medical student performance beyond that provided by academic measures alone [2,3]. Extracurricular activities are activities engaged in outside of the classroom and other than academic tasks. Examining them can be a useful way for medical school admission committees to explore the pursuits of applicants during their university years. Medical school administrators want applicants who have proven intellectual ability, maturity, leadership, and a lifelong commitment to the idea of service to society [3]. They want to evaluate predictive value of medical applicants with nonacademic abilities as
Received: December 16, 2015 • Revised: February 14, 2016 • Accepted: March 3, 2016 Corresponding Author: Sang Hyun Kim (http://orcid.org/0000-0002-5543-6878) Department of Microbiology and Immunology, Kangwon National University School of Medicine, 1 Gangwondaehak-gil, Chuncheon 24341, Korea

Tel: +82.33.250.8863 Fax: +82.33.250.8808 email: sanghyun@kangwon.ac.kr
Korean J Med Educ 2016 Jun; 28(2): 201-207.

http://dx.doi.org/10.3946/kjme.2016.25

eISSN: 2005-7288

(C) The Korean Society of Medical Education. All rights reserved. This is an open-access article distributed under the terms of the Creative Commons Attribution Non-Commercial License (http:// creativecommons.org/licenses/by-nc/3.0/), which permits unrestricted non-commercial use, distribution, and reproduction in any medium, provided the original work is properly cited. 
well as academic achievements. Involvement in extracurricular activities may have provided students with additional opportunities that fostered the development of a lifelong commitment to a medical career [2]. Balanced extracurricular activities or nonacademic experiences help extend an applicant's knowledge and development, and so are becoming more essential factors in the selection of applicants to medical school [3].

Academic accomplishments are relatively easy to objectively gauge, since transcripts are available. Assessment of nonacademic activities is more subjective. Many admission committees consider the nature and depth of involvement in the extracurricular activities, and ask applicants to submit a list of the qualities developed during their university study, or through participation in extracurricular activities [2,3]. So, medical schools usually rely on applicants' nonacademic profiles, such as selfintroduction letters, recommendation letters, and inter- views to determine their extracurricular qualities [4]. Thus, nonacademic pursuits can be such valuable secondary indices in the admission process that they should be taken into practical consideration [5].

Despite the value of extracurricular activities, little is known of nonacademic characteristics of typical medical school applicants. The purpose of this study was to quantify and describe extracurricular activities reported by applicants to the medical school of Kangwon National University in Chuncheon, Korea.

\section{Subjects and methods}

Personal profiles of 448 applicants (223 males and 225 females) who applied to Kangwon National University Medical School during the 2013 to 2014 academic year were collected. Name, address, and resident registration

Table 1. Types of Activities of Applicant Involvement in Extracurricular Pursuits

\begin{tabular}{clr}
\hline \multicolumn{1}{c}{ Area } & \multicolumn{1}{c}{ Characteristic } & Percentage reporting \\
\hline Medical volunteer/ & Hospital health service (e.g., assistance in administration, massage, washing, etc.) & 65.0 \\
community services & Overseas medical volunteering & 12.8 \\
& Shadowing & 6.4 \\
Nonmedical community & Social welfare facilities (e.g., elderly nursing home, senior welfare center, etc.) & 83.1 \\
services & Overseas nonmedical volunteering & 9.5 \\
& Education and mentoring le.g., tutoring, camp counselor, library volunteering, etc.) & 3.0 \\
& Volunteering for rural communities & 2.0 \\
& Religious organizations & 1.1 \\
Nlub activities & Neighborhood clean-up events & 0.8 \\
& Sports and recreation (e.g., bowling, skiing, bodybuilding, yacht, etc.) & 20.8 \\
& Community volunteering (e.g., teaching assistant, clean-up events, etc.) & 17.3 \\
& Student government & 16.5 \\
& Arts and culture (e.g., choir, band, orchestra, drama, painting, etc.) & 13.3 \\
& Religious organizations & 12.5 \\
& Academic activities (e.g., writing/poetry groups, etc.) & 12.5 \\
& Newspaper/broadcasting & 4.1 \\
Club officials & Club president & 41.7 \\
& Student government staff & 37.5 \\
& Newspaper editor/broadcasting director & 20.8 \\
Research works & Data collection and analysis & 79.1 \\
& Equipment-cleaning & 7.5 \\
& Specialized topics studies & 6.0 \\
\hline
\end{tabular}


number of applicants were anonymized.

Extracurricular activities or nonacademic pursuits are those that fall outside the scope of the academic curriculum of university education. They comprised participation in medical volunteer/community services, nonmedical community services, club activities, club officials, and research works [6]. Two well-informed researchers with a master degree classified the data (Table 1). If there is a disagreement, different opinions prompted re-examination of the data and consensual agreement about the findings.

Frequency analysis and chi-square test were used to determine significant differences in all extracurricular characteristics. Independent samples t-test was used to compare the mean in volunteer hours of foreign and domestic college graduates. Pearson simple correlation coefficient was used to measure the strength of the linear relationship between the extracurricular activity areas. SPSS version 21.0 (IBM Corp., Armonk, USA) was used for all data analyses.

\section{Results}

\section{Characteristics of extracurricular activities}

Of the 448 applicants participating in extracurricular activities, $15.3 \%$ had performed medical-related community services. Shadowing a doctor, working as volun- teers in a health care setting, was done by only $6.4 \%$ of applicants. Club activities were reported by $22.9 \%$ of applicants, 10\% had experience in club officiating, and 13.4\% had carried out research. Nonmedical community services were the most commonly reported extracurricular activities (39.8\%) (Table 2). On average, applicants participated in 0.3 medical volunteer/community service, 1 nonmedical community service, and 0.7 club activity. Research per applicant was 0.3. Thirty-one of applicants (6.9\%) had published research they were involved with in a research journal or presented a poster. There were no correlations between medical volunteer/community services, nonmedical community services, club activities, and research. Forty-nine of all applicants (10.9\%) were successful applicants. There were no statistically significant relationships between successful and unsuccessful applicants in extracurricular activities (Table 3). Sixteen percent reported overseas volunteer experience comprising foreign medical mission trips (6\%), and overseas nonmedical volunteer experiences (10\%). Twenty-five countries were totally mentioned in the list of medical mission trips, most often the Philippines $(n=9)$, followed by Vietnam $(n=5)$, India $(n=5)$, Kenya $(n=5)$, Uganda $(n=5)$, Cambodia $(n=4)$, Thailand $(n=4)$, and Nepal $(n=4)$.

Male and female applicants who had performed medical-related volunteer/community services reported an average participation of 44.4 hours and 51.8 hours, respectively (Table 2). Average participation in

Table 2. Nonacademic Characteristics of Applicants

\begin{tabular}{lcccccccc}
\hline \multirow{2}{*}{ Area } & \multicolumn{3}{c}{ Percentage reporting } & & \multicolumn{3}{c}{ Average per applicant (hr) } \\
\cline { 2 - 3 } \cline { 7 - 9 } & Male & Female & Total & & Male & Female & Total \\
\hline Medical volunteer/community services & 12.3 & $18.3^{*}$ & 15.3 & & 44.4 & $51.8^{*}$ & 47.9 \\
Nonmedical community services & 37.7 & 42.0 & 39.8 & & 27.3 & 25.7 & 27.0 \\
Club activities & $17.6^{*}$ & $28.1^{*}$ & 22.9 & & - & - & - \\
Club officials & 8.3 & 11.8 & 10.0 & & - & - & - \\
Research works & $10.0^{*}$ & $16.7^{*}$ & 13.4 & & - & - & - \\
\hline
\end{tabular}

${ }^{*} p<0.05$. 
Table 3. Nonacademic Characteristics of Successful and Unsuccessful Applicants

\begin{tabular}{lccccc}
\hline \multirow{2}{*}{ Area } & \multicolumn{2}{c}{ Percentage reporting } & & \multicolumn{2}{c}{ Average per applicant (hr) } \\
\cline { 2 - 3 } \cline { 5 - 5 } & Successful applicant & Unsuccessful applicant & & Successful applicant & Unsuccessful applicant \\
\hline Medical volunteer/community services & 14.5 & 15.6 & 46.2 & 48.1 \\
Nonmedical community services & 45.1 & 39.2 & & 25.8 & 27.1 \\
Club activities & 23.2 & 22.5 & & - \\
Club officials & 10.4 & 10.0 & - & - \\
Research works & 14.2 & 13.5 & & - & - \\
\hline
\end{tabular}

Table 4. Profile of Nonacademic Characteristics of Foreign and Domestic College Graduates

\begin{tabular}{|c|c|c|c|c|c|c|}
\hline \multirow[t]{2}{*}{ Area } & \multicolumn{3}{|c|}{$\begin{array}{l}\text { Percentage reporting } \\
\text { in foreign college graduates }\end{array}$} & \multicolumn{3}{|c|}{$\begin{array}{c}\text { Percentage reporting } \\
\text { in domestic college graduates }\end{array}$} \\
\hline & Male & Female & Total & Male & Female & Total \\
\hline Medical volunteer/community services & 26.4 & $35.8^{*}$ & $31.1^{*}$ & 9.2 & $14.1^{*}$ & $11.6^{*}$ \\
\hline Nonmedical community services & 34.0 & 30.2 & 32.1 & 33.7 & 38.4 & 36.0 \\
\hline Club activities & 17.0 & $32.1^{*}$ & 24.5 & 13.6 & $24.6^{*}$ & 19.1 \\
\hline Club officials & 11.3 & 11.3 & 11.3 & 6.9 & 10.5 & 8.7 \\
\hline Research works & 18.9 & $35.8^{*}$ & $27.4^{*}$ & 7.8 & $12.5^{*}$ & $11.3^{*}$ \\
\hline
\end{tabular}

${ }^{*} p<0.05$.

Table 5. Profile of Volunteer Hours of Foreign and Domestic College Graduates

\begin{tabular}{lcccccccc}
\hline \multirow{2}{*}{\multicolumn{1}{c}{ Area }} & \multicolumn{3}{c}{ Average per applicant } & & \multicolumn{3}{c}{ Average per applicant } \\
& in foreign college graduates & (hr/yr) & & \multicolumn{2}{c}{ in domestic college graduates (hr/yr) } \\
\cline { 2 - 4 } \cline { 7 - 9 } & Male & Female & Total & & Male & Female & Total \\
\hline Medical volunteer/community services & 130 & 166 & $148^{*}$ & & 32.9 & 36.5 & $34.5^{*}$ \\
Nonmedical community services & 160 & 129 & $145^{*}$ & & 9.5 & 11.8 & $11.2^{*}$ \\
\hline
\end{tabular}

${ }^{*} p<0.05$.

nonmedical community services was 27.3 and 25.7 hours per applicant in the same respective order (Table 2). Males/females detailed 10/17 foreign medical volunteer experiences, and 15/28 foreign nonmedical volunteer trips.

\section{Extracurricular activities of applicants from foreign universities}

Fifty three of all applicants (11.9\%) were foreign college graduates; of these, $25(47.1 \%)$ were male and 28 (52.9\%) were female. Domestic college graduates com- prised 395 applicants (88.1\%); of these, 198 applicants (50\%) were male and 197 (50\%) were female (Table 4). The eight of foreign college graduates (15\%) who had their work published in a research journal or presented a poster exceeded by 2.6 times the $5.8 \%$ rate of domestic college graduates. Over half $(54.7 \%)$ reported overseas volunteer experiences, with foreign medical mission trips for $22.6 \%$ and overseas nonmedical volunteer services for $32 \%$. For females, seven applicants each had foreign medical volunteer experience and foreign nonmedical experience (25\% each). For males, five (20\%) professed 
overseas medical volunteer experience, and 10 (40\%) reported overseas nonmedical volunteer experience. Applicants from foreign universities in medical-related volunteer/community services reported with an average of 148 hours compared to 34.5 hours of applicants from domestic universities (Table 5). Applicants from foreign universities in nonmedical volunteer/community services reported an average of 145 hours compared to 11.2 hours for applicants from domestic universities, representing 12.9 times more volunteer hours (Table 5).

\section{Discussion}

Nonacademic qualities can assist in identifying desirable applicant personalities, so most medical schools take nonacademic pursuits into consideration in evaluating an applicant's personal qualities [3,4]. Though applicants need high GPA and MEET scores because of highly competitive admission to medical school, extracurricular experiences that demonstrate compelling qualities are also valuable in guiding admission approval. Specifically, participation in extracurricular activities can demonstrate an applicant's positive qualities, leadership potential, desire for personal growth, and long-term societal dedication. Contrary to our expectations, there was no statistically significance between successful and unsuccessful applicants in nonacademic pursuits (Table 3). Since academic achievements comprise a large proportion in selection factors, extracurricular activities have little impact on an admissions decision under the current medical school admissions system.

The types of volunteer activities that applicants engage in matter to medical school admission. The extracurricular activity most valued by medical schools is medical-related community service; this can demonstrate interest in medicine in general and resolve to become a physician. Volunteer work in a health setting does not imply health-related activity. Shadowing a doctor, which will allow students to gain exposure to patients in a medical setting, is the nature of the activity that holds more sway [7]. The experience helps applicants get a more complete picture of the medical profession [7].

In contrast to medical-related community services, nonmedical community services will truly demonstrate dedication to public service. Nonmedical volunteer services with a humanity organization like Habitat for Humanity, or participating in, as two examples, public education and environmental clean-ups, can provide broad exposure to environments of cultural diversity.

Leadership experience, such as holding an office in student government/club/organization, or becoming the team captain for a sport played during university years is looked on favorably by admission committees. A study that addressed the influence of student leadership positions on the lives of students up to three decades after graduation suggested that prior student leadership experience positively influenced future organizational involvement [8]. Involvement in basic research can clarify academic interests in medicine and can lay the foundation for future research productivity [9].

Female applicants participated significantly more than males in medical volunteer/community service, club activities, and research than males. Females spent significantly more medical volunteer time than did males, while males and females spent similar nonmedical volunteer hours (Table 2). Females reported participating in significantly greater numbers of overseas volunteer experiences than males. Dawson et al. [10] reported that academic accomplishments alone did not explain the difference between performance of male and female medical students. Other researchers have found that for women, admission interview ratings, prior health care 
experience, personality valuables, and demographic factors are more predictive than are academic factors $[11,12]$. Thus, there may be some significant differences in gender. In this study, females consistently reported greater participation across almost the whole nonacademic pursuits.

Applicants from foreign universities reported participating in significantly greater numbers of both medical volunteer/community services and research than applicants from domestic universities. There was also a gender difference in extracurricular activities between applicants from both foreign and domestic universities. Both female foreign and domestic college graduates reported greater participation in medical volunteer services, club activities, and research than males (Table 3).

The previous and present results demonstrate the extensive participation in extracurricular activities for medical school applicants. This small sample size of applicants and limitation of personal data in this study may limit the interpretation of these results. The potential differences observed suggest the need for further studies. This study will help admission committees in recruiting applicants who will be successful in medical school, and will help in making comparisons between applicants with similar academic achievements.

ORCID: Sang Hyun Kim: http://orcid.org/0000-0002-5543-6878

Acknowledgements: I appreciate the support by members of the Department of Microbiology and Immunology, Kangwon National University School of Medicine, Chuncheon, Korea.

Funding: This study was supported by 2014 Research Grant from Kangwon National University (number: 120140303).

Conflicts of interest: None.

\section{References}

1. Mitchell KJ. Traditional predictors of performance in medical school. Acad Med 1990; 65: 149-158.

2. Lumley S, Ward P, Roberts L, Mann JP. Self-reported extracurricular activity, academic success, and quality of life in UK medical students. Int J Med Educ 2015; 6: 111-117.

3. Hulsman RL, van der Ende JS, Oort FJ, Michels RP, Casteelen G, Griffioen FM. Effectiveness of selection in medical school admissions: evaluation of the outcomes among freshmen. Med Educ 2007; 41: 369-377.

4. Kim SH. Analysis of characteristics shown in self introduction letter and professor's recommendation letter. Korean J Med Educ 2013; 25: 189-199.

5. Webb CT, Sedlacek W, Cohen D, Shields P, Gracely E, Hawkins M, Nieman L. The impact of nonacademic variables on performance at two medical schools. J Natl Med Assoc 1997; 89: 173-180.

6. Mentasti LE, Thibodeau EA. Nonacademic characteristics of dental school applicants. J Dent Educ 2006; 70: 1043-1050.

7. Shankar N, Singh S, Gautam S, Dhaliwal U. Motivation and preparedness of first semester medical students for a career in medicine. Indian J Physiol Pharmacol 2013; 57: 432-438.

8. Schuh JH, Laverty M. The perceived long-term influence of holding a significant student leadership position. J Coll Stud Pers 1983; 24: 28-32.

9. Nikkar-Esfahani A, Jamjoom AA, Fitzgerald JE. Extracurricular participation in research and audit by medical students: opportunities, obstacles, motivation and outcomes. Med Teach 2012; 34: e317- e324.

10. Dawson B, Iwamoto CK, Ross LP, Nungester RJ, Swanson DB, Volle RL. Performance on the National Board of Medical Examiners Part I examination by men and women of different race and ethnicity. JAMA 1994; 
272: 674-679.

11. Calkins EV, Arnold LM, Willoughby TL. Gender differences in predictors of performance in medical training. J Med Educ 1987; 62: 682-685.
12. Willoughby L, Calkins V, Arnold L. Different predictors of examination performance for male and female medical students. J Am Med Womens Assoc 1979; 34: 316-317, 320. 